\title{
Evaluation of Curriculum Implementation and Curriculum Modifications in Inclusive Schools
}

\author{
Imam Yuwono \\ Universitas Lambung Mangkurat \\ Banjarmasin, Indonesia \\ imam.plb@ulm.ac.id
}

\begin{abstract}
This evaluation study aims to determine the effectiveness of implementing school curriculum modification of inclusive education providers of primary schools in the city of Banjarmasin. Evaluation uses the CIPP model (context, input, process, product). Data were analyzed using qualitative descriptive techniques, developed by Glickman with quadrant type. Research findings showed that the implementation of curriculum modification is positioned in quadrant IV (less effective) seen from differentiated curriculum indicators (- - - ), containing social aspect $(-+--)$, takes a social attitude $(-+--)$, curriculum flexibility (+ - - - -). There is only one variable which gives effective contribution (positive) in each component. Most indicators contribute less effectively (negatively).
\end{abstract} school

Keywords-evaluation; curriculum modification; inclusive

\section{INTRODUCTION}

Different issues related to children with special needs in inclusive schools, among others, are: a) appropriate and proportionate curriculum to be used as reference in learning; b) limited ability of teachers to develop special curriculum for children with special needs; c) limited facilities and infrastructure and; d) difficulties for teachers in assessing the ability of children with special needs [1]. Understanding teacher and headmaster's school to guide curriculum modification shows excellent criteria about 46, $93 \%$ of teachers in inclusive schools in Banjarmasin who have difficulty in modifying the curriculum [2]. But there are reports that the teachers in inclusive schools do not make curriculum modifications [3]. Curriculum used in inclusive school indeed do not only the general/regular curriculum, because the regular curriculum is only suitable for normal children and have similar abilities. Children with special needs in inclusive schools should use a special curriculum that is modified according to needs for individual participants of the students. For the successful implementation of inclusive education in schools, there are needs for curriculum adaptation, potential educational changes across sectors and environmental adaptation. The primary purpose of curriculum modification is that the students can receive learning by individual abilities and the teachers will more easily achieve quality of learning for the students [4]. Inclusive education requires the application of a flexible curriculum, adjustment of learning materials, evaluation, tools, and structuring the children's learning environment according to their needs [5].

\section{LITERATURE REVIEW}

\section{A. Inclusive Education}

Inclusive education is a concept that covers all children without exception. Inclusion assumes that living and learning together are better ways, which can provide benefits for everyone, not just children who are labeled as having a difference but for all children with their uniqueness. Inclusive education involves changes and modifications of content, approach, structure, and strategy, with a shared vision that includes all children in the same age range and a belief that inclusion is the responsibility of a regular system that educates all. Inclusive education regarding activities provides an appropriate response to a broad spectrum of learning needs both in formal and non-formal education settings. Inclusive education aims to reduce concerns and build, foster loyalty in friendship and build understanding and respect [6]. The objectives of inclusive education listed in the Salamanca statement include: (1) that all children have a wide diversity in their characteristics and needs, (2) all schools have a perception that differences are normal, so schools need to accommodate all children, (3) children with disability should go to school in the neighborhood, (4) increase community participation in the importance of education held in inclusion, (5) change the paradigm of teacher-centered teaching into student-centered teaching, (6) the implementation of a flexible curriculum should be adjusted to children's needs, not the other way around, (7) schools can provide benefits to all children without discrimination, helping to create an inclusive society. Inclusion improves the efficiency and cost-effectiveness of education, (8) by implementing inclusive education, at least we do not need to build new infrastructure to send children with special needs to study [4] [6].

Inclusive education means creating and maintaining a warm class community, accepting diversity, and respecting differences. The teacher has the responsibility of creating a classroom atmosphere that accommodates all children by emphasizing the social class atmosphere that respects differences regarding the ability of physical conditions, socioeconomic, ethnic, religious, and so on. Classroom management in heterogenous class and filled with individual differences requires fundamental changes in the curriculum. Inclusive teachers will consistently shift from rigid learning, based on textbooks, or teaching material to learning that involves a lot of cooperative learning, thematic, critical thinking, problem solving, and authentic assessment. Inclusive education means 
demanding the application of a multilevel and multimodality curriculum. An inclusive class means learning is no longer centered on the curriculum but on how to teach with childcentered principle, with the consequence of significant flexibility in the curriculum and application of individual program services or group process approaches in the implementation of the multilevel and multimodality curriculum. Inclusive education means preparing and encouraging teachers to teach interactively. Changes in the curriculum are closely related to changes in learning methods. The traditional class model in which a teacher struggles alone to meet the needs of all children in the classroom must be replaced by a model of students that enables for working together, teaching each other, and actively participating in their education and the education of their friends. The curriculum developed in schools that provide inclusive education is the national curriculum by the level of schools providing inclusive education. The curriculum is developed by the school by the conditions and needs of the students. Modified curriculum development enables the regular students and students with special needs can access the curriculum naturally. Curriculum flexibility and scoring systems are unique characteristic curriculum in schools providing inclusive education [5] [6].

\section{B. Curriculum Modification}

Inclusion schools conduct curriculum development for children with special needs according to their learning abilities and needs. Development is conducted by adapting and modifying. Curriculum adaptation is the procurement and adjustment of materials and learning techniques that can help children to attend the same learning as their peers. Curriculum modification refers to changes in curriculum for the benefit of children individually by reducing the difficulty and quantity of children's learning tasks. Proper and operational curriculum development can be carried out by referring to the assessment results. General students and special needs who have average intelligence potential and above the average enforced national standard curriculum, students with special needs who have intelligence potential below average enforced adaptation and modification curriculum, while for the students who are classified as special intelligent and special talents used escalation curriculum.

Modified and adapted curriculum is the national standard curriculum that is modified according to the talents, interests, and potential of students who have special needs. Modification of the curriculum is carried out by each educational unit that organizes inclusive education. The target of developing the inclusive education curriculum is focused on aspects of Competency Standards (SK), Basic Competencies (KD), indicators of material, process and evaluation. The implementation of inclusive education in regular schools does not have to create a separate curriculum. The curriculum used is the curriculum applied at the school. However, the curriculum used must have the opportunity to be modified, when there are students who have barrier to the implementation of the existing curriculum or there are students who can go beyond the existing curriculum. The such curriculum is called a flexible curriculum. Curriculum modification is necessary so that each student gets learning that is appropriate to the individual student's condition. The students who need curriculum modification are determined based on the results of identification and assessment [7]. The duplication model means developing a curriculum for children with special needs the same or similar to students in general. Substitution model means replacing something in the general curriculum with others because it is impossible to apply to children with special needs. The omission model means that something in the curriculum is not conveyed to children with special needs because it is too difficult or not by children's needs [3].

Various ways of modifying the curriculum in inclusive education are (1) process modification, as much as possible to become the first alternative according to the results of identification and assessment, so that the students can follow the existing curriculum. Process modification is needed with the reason students will meet barrier or problem learning if the existing curriculum is implemented/taught in the same way as children in general. The curriculum can be followed by students if modified in the process. Process modification consists modification of teaching aids, setting of space, method of teaching, tolerance of students' different ways of learning, (2) modification of curriculum content; this modification consists of modifying the level of learning difficulties. Substitution modification, in which the material taught to children with special needs is replaced with other material. Try to replace only the material, not the subjects. Replacement of subjects must be supported by correct arguments. Modification of omission refers to the removal of material/subjects. This modification is applied if it is no longer possible to substitute material/subjects that are appropriate to the conditions and needs of the children [3].

Inclusive education programs lead to large demands on regular teachers and special educators. This program demands a substantial shift from tradition to teaching students the same material in the class, to teaching each child according to their individual needs, but in class settings. Students have a variety of field interests and different levels of mastery of material and learning strategies.

The inclusive education curriculum model consists of (1) regular curriculum models, (2) regular curriculum models with modifications, (3) curriculum models for Individualized Education Programs (IEP). The regular curriculum model, which is a curriculum that includes students with special needs to follow the regular curriculum as well as other friends in the same class. The regular curriculum model with modifications, namely the curriculum that is modified by the teacher in the learning strategy, type of evaluation, as well as in other additional programs while still referring to the needs of students with special needs. This model can have special needs students who should learn with Individualized Education Programs (IEP). The IEP curriculum model is a curriculum prepared by the IEP program teacher that was developed with a development team involving class teachers, special education teachers, principals, parents, and other relevant experts. Individualized Education Program (IEP) is the most prominent characteristic of inclusive education. The concept of inclusive education with the principle of equality requires an adjustment of learning models that are responsive to individual differences. Then the IEP becomes something that needs more emphasis 
[8]. IEP serves the unique needs of students and is a service provided to achieve the desired goals and how the effectiveness of the program will be determined [8] [9].

\section{METHOD}

This study is a program evaluation study that is oriented towards achievement, the suitability of the results of the evaluation of the implementation of inclusive education programs for elementary schools in Banjarmasin with the evaluation criteria established. Based on the ontology, the approach used in this evaluation research is the CIPP model evaluation approach (context, input, process, product) [10]. Program evaluation criteria below:

TABLE I. PROGRAM EVALUATION

\begin{tabular}{|c|c|c|}
\hline Component & Rated aspect & Evaluation Criteria \\
\hline \multirow[t]{4}{*}{$\begin{array}{l}\text { Curriculum } \\
\text { modification }\end{array}$} & $\begin{array}{l}\text { Differentiated } \\
\text { curriculum }\end{array}$ & $\begin{array}{l}\text { The curriculum is organized } \\
\text { based on individual differences } \\
\text { in students } \\
\text { The curriculum is organized } \\
\text { based on children needs } \\
\text { Curriculum content is adjusted } \\
\text { to the level of development of } \\
\text { students individually }\end{array}$ \\
\hline & $\begin{array}{l}\text { The curriculum is } \\
\text { centered on students }\end{array}$ & $\begin{array}{l}\text { The curriculum requires active } \\
\text { student learning } \\
\text { Curriculum content encourages } \\
\text { collaborative learning. The } \\
\text { change from teacher-centered } \\
\text { learning to student centered } \\
\text { learning }\end{array}$ \\
\hline & 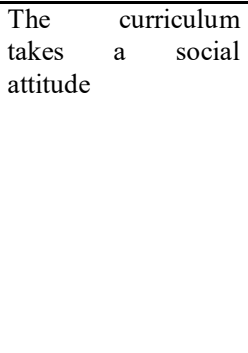 & $\begin{array}{l}\text { Curriculum content contains } \\
\text { cooperative behavior, help, and } \\
\text { respect } \\
\text { Curriculum content encourages } \\
\text { teachers to carry out the } \\
\text { learning process to all aspects } \\
\text { of child development including } \\
\text { attitudes } \\
\text { Curriculum content encourages } \\
\text { teachers to assess student } \\
\text { attitudes }\end{array}$ \\
\hline & Flexible curriculum & $\begin{array}{l}\text { Curriculum content is flexible } \\
\text { enough to suit student } \\
\text { conditions } \\
\text { The approach used by the } \\
\text { teacher in the teaching and } \\
\text { learning process varies } \\
\text { Assessment systems in the } \\
\text { curriculum are flexible enough } \\
\text { to adjust students' abilities }\end{array}$ \\
\hline
\end{tabular}

The data obtained were analyzed qualitatively using the CIPP model by triangulating the relevant data to the implementation of inclusive education programs by referring to the criteria set. Then the interpretation and conversion of the mapping of the achievement of indicators is whether it is appropriate or not under the evaluation criteria that have been set. If it matches with the evaluation criteria, it is given a positive sign $(+)$ or is called effective, if it is not by the specified evaluation criteria, it is given a negative sign (-) or is called ineffective. The next step is to do quadrant mapping according to the evaluation criteria that have been set. The mapping of the effectiveness of the implementation of inclusive education programs for elementary schools in Banjarmasin refers to the Glickman quadrant prototype bellow:

\section{1) Quadrant I (Very Effective)}

In quadrant, I (very effective) shows all components that are evaluated in context, input, process, product, outcome is positive or meets the specified evaluation criteria.

\section{2) Quadrant II (Effective enough)}

In quadrant II (effective enough) shows almost all components evaluated, input, process, product, outcomes are positive or meet the evaluation criteria specified. Only one of the five components is negative (not by evaluation criteria)

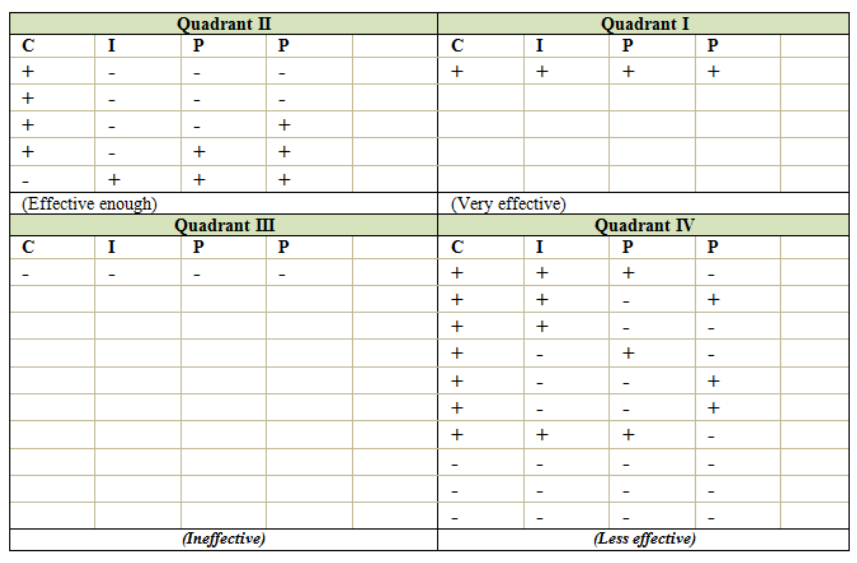

Fig. 1. Prototype of the Glickman Quadrant

\section{ReSUlt AND DisCUSSION}

\section{A. Result}

In principle, inclusive education curriculum is same as regular curriculum. Curriculum used is the regular school curriculum that organizes inclusive education. Curriculum modified according to the ability of students, there is no specific curriculum, to the school of inclusive education providers. The implementation of this curriculum modification is viewed from four indicators that describe the implementation of an inclusive curriculum. The first indicator is a curriculum that is differentiated or is often referred to as a curriculum based on individual differences. The second is curriculum oriented to the learner. The third is curriculum that have a social attitude. The fourth is a flexible curriculum, which has enough space to move and not to be rigid, to adjust to the child's condition.

\section{1) Differentiated curriculum data}

The differentiated curriculum in this study is translated into four components, namely: individual learning programs, accommodating student's needs, diversity of teaching materials, and appreciating differences. The curriculum data differentiates the three inclusive schools bellow: 
TABLE II. The CURricUlum DATA DifFERENTIATES

\begin{tabular}{|c|c|c|c|l|}
\hline \multirow{2}{*}{ Indicators } & \multicolumn{3}{|c|}{ School name (\%) } & Average \\
\cline { 2 - 5 } & $\boldsymbol{A}$ & $\boldsymbol{B}$ & $\boldsymbol{C}$ & \\
\hline EIP (educational individual programs) & 50 & 40 & 40 & 40 \\
\hline Accommodate student needs & 40 & 40 & 50 & 40 \\
\hline Material diversity & 40 & 50 & 50 & 46.6 \\
\hline Appreciate differences & 50 & 50 & 50 & 50 \\
\hline
\end{tabular}

There only three schools that provide inclusive education with only $40 \%$ of teachers who use individual educational programs (EIP), $40 \%$ of the curriculum has accommodated the needs of children, $46.6 \%$ of the curriculum has appreciated the diversity of students, and $5 \%$ respects individual differences.

\section{2) Curriculum data oriented to students}

Data on the implementation of curriculum modification on the indicators adapted to students, regarding four components, namely: the curriculum is student-centered, real learning, togetherness, and competition with himself not with others. The data obtained bellow:

TABLE III. The CURriculum DATA ORIENTED TO STUDENTS

\begin{tabular}{|c|c|c|c|c|}
\hline \multirow{2}{*}{ Indicator } & \multicolumn{3}{|c|}{ School name } & Average \\
\cline { 2 - 5 } & $\boldsymbol{A}$ & $\boldsymbol{B}$ & $\boldsymbol{C}$ & \\
\hline Student-centered & 50 & 50 & 50 & 50 \\
\hline Learning towards the concrete & 70 & 80 & 80 & 76.6 \\
\hline Togetherness & 40 & 40 & 50 & 43.3 \\
\hline Competition with himself & 40 & 30 & 30 & 33.3 \\
\hline
\end{tabular}

Data obtained from questionnaires about the implementation of curriculum modification obtained data, only $50 \%$ of teachers who implemented the curriculum were student-centered, $76.6 \%$ of teachers conducted concrete learning, $43.3 \%$ of teachers created peace, and to achieve learning objectives and only $33.3 \%$ have a perception that competition truly with our ownself is not with others.

3) Data on curriculum implementation containing social aspects

Data on the implementation of the curriculum containing social aspects, outlined into four components, namely, efficiently helping each others, peer tutorials, learning to use various sources of information and cooperation with parents. Data presented in the table bellow:

TABLE IV. DATA ON CURRICULUM IMPLEMENTATION CONTAINING SOCIAL ASPECTS

\begin{tabular}{|c|c|c|c|l|}
\hline \multirow{2}{*}{ Indicator } & \multicolumn{3}{|c|}{ School name (\%) } & \multirow{2}{*}{ Average } \\
\cline { 2 - 4 } & $\boldsymbol{A}$ & $\boldsymbol{B}$ & $\boldsymbol{C}$ & \\
\hline Easily helping each others & 40 & 50 & 50 & 46.6 \\
\hline Totorial peers & 60 & 60 & 60 & 60 \\
\hline Resources & 50 & 50 & 50 & 50 \\
\hline Collaborate with parents & 40 & 40 & 40 & 40 \\
\hline
\end{tabular}

Based on the results of the three inclusive school questionnaires, data were obtained: $46.6 \%$ of teachers were able to foster mutual assistance in learning, $83.3 \%$ of teachers were able to teach material by utilizing peer tutorials. $80 \%$ of teachers have collaborated with parents in facilitating the learning process.

\section{4) Data flexibility in curriculum}

Curriculum flexibility in this study is a curriculum that is not rigid, enough to provide flexibility to adjust to the conditions of students. The flexibility component of the curriculum is, the curriculum adapts to the environment, the selection of teaching materials by the abilities of the child and based on the results of the assessment before the implementation of learning, individual curriculum learning strategies that vary according to student learning styles. Curriculum flexibility data bellow:

TABLE V. DATA FLEXIBILITY IN CURRICULUM

\begin{tabular}{|c|c|c|c|l|}
\hline \multirow{2}{*}{ Indicator } & \multicolumn{3}{|c|}{ School name (\%) } & Average \\
\cline { 2 - 5 } & $\boldsymbol{A}$ & $\boldsymbol{B}$ & $\boldsymbol{C}$ & \\
\hline Adapting the environment & 80 & 70 & 90 & 80 \\
\hline Material selection & 50 & 50 & 50 & 50 \\
\hline Based on assessment & 40 & 40 & 40 & 40 \\
\hline Individual curriculum & 50 & 50 & 50 & 50 \\
\hline Learning strategies & 40 & 50 & 40 & 43.3 \\
\hline
\end{tabular}

The three schools that provide inclusive education can implement the curriculum by adapting the environment and selecting material by $80 \%$ of the total number of teachers, $76.6 \%$ of teachers have conducted learning based on assessment results. The average school is less able to design an individual curriculum, conduct effective learning strategies and organize classes.

\section{B. Discussion}

The implementation of curriculum modification in the first oror's index is a differentiated curriculum or is often called a curriculum based on individual differences. The three schools for inclusive education providers in Banjarmasin carry out Individual Learning programs that are less effective, i.e. only $40 \%$ of teachers can make PPI, most teachers cannot create PPI programs to adapt the material to the conditions of individual students. The lack of teacher knowledge about children will make it difficult to identify children's needs [11]. All the school education providers inclusive less effective is $40 \%$ who can design the curriculum according to the needs of students. The teacher is not responsible for the students with special needs [12]. The diversity of material to adapt to the conditions/needs of children individually is carried out by the school only $46.6 \%$, meaning that the school is still using classical subject matter, not paying attention to individual differences different each other. Ref [6] needs a shift from the tradition of teaching students the same material in class, to teaching each child according to their needs. The three schools have not been reflected in respecting individual differences, as evidenced by research data, only $50 \%$ of curricula that value individual differences.

The modified curriculum is less effective towards students. The implementation of a curriculum that is centralized to students by $50 \%$, curriculum designed is still the dominant teacher who is active in learning. In written learning design students are active, but in reality, the implementation of learning is dominated by the teacher as the speaker, This is in line with Borko's opinion, 1996 that the importance of teacher's knowledge and understanding of learning strategies will affect 
the teaching and learning situation. Nevertheless, 76, 6\% of teachers do the learning abstract to the concrete, the teachers facilitate learning how students see the lesson concepts. Data about learning that motivates students to learn and solve problems together is not yet effective, only for 43.3 teachers who can trigger learning to solve common problems or train together in learning. By the opinion of In inclusive education student competition is not with other students, but competed with students themselves. The reality in three inclusive schools in Banjarmasin is only 33, $3 \%$ of teachers compete with students themselves. The class ranking system is still applied at the end of each student's learning evaluation results.

The values of social attitudes that should be developed in the inclusive education curriculum, including interacting with each other, help learn to function with each other, strengthen each other, tolerate, develop cooperation rather than compete, understand that all children have different needs from majority [11]. Data obtained through this study, that the implementation of curriculum modification in the aspect of developing social attitudes is mutual assistance at $44.6 \%$, learning with peer tutorials at 60 , learning as a source of information $50 \%$ and working with parents $40 \%$.

The flexible curriculum is necessary in schools that provide inclusive education. Inclusive students have varying levels of interest in the field and a mastery of the material, and learning strategies variation, it is necessary to differentiate the curriculum. The curriculum is structured by adjusting students' conditions [6]. Data on curriculum flexibility in elementary schools for inclusive education in Banjarmasin City has not been effective. The curriculum has adapted to the environment achieved $80 \%$, flexibility in selecting materials and teaching materials $50 \%$, selecting teaching materials according to the results of assessment of student needs $40 \%$, teachers who design individual learning programs $50 \%$, learning strategies that adjust to the condition of students was $43.3 \%$, organizing to welding was effective at $43.3 \%$. The classes created do not work together to help each other. The curriculum of inclusive education should be directed so that all group members interact with one another, cooperation, tolerance to realize that some children have different needs than the majority [11].

\section{CONCLUSION}

The five indicators of curriculum flexibility that have been implemented have not been effective, according to the evaluation criteria. The curriculum that is arranged is less flexible to adjust the condition of the child. One profile in inclusive school is implementing a flexible curriculum, to create a warm classroom, embrace diversity and respect for diversity.

\section{REFERENCES}

[1] A. Salim, "Education for Children with Special Needs Inclusively," J. ICSAR, vol. 1, no. 1, pp. 32-35, 2017.

[2] I. Yuwono, "CIPPO Evaluation at School Providing Inclusive Education at Elementary School," J. ICSAR, vol. 1, no. 2, 2017.

[3] E. Nindia, "Learning Implementation for Hearing Obstruction Students in Inclusive Education Schools," J. Spec. Educ. UNJ, 2016.

[4] B. H. Johnsen and M. Skjorten, Towards Inclusion, Special Needs Education An Introduction, Bandung: UPI Bandung Graduate Program, 2003

[5] S. Shepin, Managing Special Education, Boston: Open University Pers, 2005.

[6] Skjorten, Towards Inclusion of Special Needs Education An Introduction, Bandung: UPI Postgraduate Program, 2003.

[7] Directorate of PSLB, Educational Implementation Guidelines Inclusive, Jakarta: Directorate of PKLK, 2009.

[8] J. BH, Curriculum for individual learning needs plurarity, Bandung: Postgraduate UPI, 2003.

[9] T. M. Stephens, Teaching mainstreamed students, Canada: John Wiley \& Sons, 1992.

[10] D. L. Stufflebeam, Viewpoints model evaluation on educational and human services evaluation, Boston: Kluwer Academic Publisher, 2001.

[11] B. Johsen, Towards Inclusive, Inclusive education an introduction, Bandung: UPI Bandung Graduate Program, 2003.

[12] D. P. Hallahan, Exceptional learnes: An Introduction to Special Education, Boston: Person Education Inc, 2009. 